\title{
The Architecture of the Avian Gut and Tolerance of Grude Fibre
}

\section{By E. T. Halnan, School of Agriculture, University of Cambridge}

The digestive tract of the fowl consists essentially of a hollow muscular tube lined internally with epithelium and modified at intervals along its length to form characteristic chambers or organs, each of which is peculiarly adapted for the function with which it is associated. As with other farm animals, the gut is distinguished histologically into several layers or coats: (I) an external connective tissue coat which in part is continuous with the peritoneum, (2) a muscular layer, usually comprising an external longitudinal layer and an internal circular layer, (3) a connective tissue layer or submucous layer, and (4) the mucous coat, comprising the muscularis mucosae if present and the epithelium lining the lumen of the gut.

As regards the mouth and mouth parts of the fowl, the chief points of interest are the extreme mobility of the lower jaw, the substitution of a pointed, horny beak for lips and cheeks, and the semi-rigid arrowhead-shaped tongue, which fills the narrow triangular-shaped cavity of the mouth. The extreme mobility of the lower jaw is due to the loose character of the articulation, but particularly to the quadrate bone interposed between the skull articulation and the mandibular articulation, and enabling the mouthopening to be widely distended.

In the centre of the tongue along its length is the entoglossal bone; this in turn is surrounded by a connective tissue coat containing blood, lymph vessels, nerves and salivary glands. The muscular tissue of the tongue is scant in amount, being almost absent at the tip, but the hyoid muscles which produce the tongue movements are well developed. The tongue is covered throughout with a stratified squamous epithelium, which is smooth and thin on the lower or ventral surface, except at the tip, but is thick and horny on the dorsal or upper surface of the tongue and especially at the tip. The mouth cavity is lined throughout with squamous stratified epithelium, and numerous mucous salivary glands are found in the submucous layer, i.e. in the floor and roof of the mouth, in the angles of the beak, in the tongue and in the pharyngeal region. There is no soft palate, and the hard palate is pierced by a medial slit which communicates with the nasal cavities. There is no clear demarcation between the pharynx and the rest of the mouth cavity, but the pharyngeal region is regarded as extending from a row of papillae situated at the back of the hard palate to a row of papillae at the entrance to the oesophagus. In the roof of the pharynx is a small medial slit which forms the common opening of the eustachian tubes, and on the floor close to the oesophageal opening is another medial slit forming the entrance to the anterior larynx.

The oesophagus or gullet is a very distensible muscular tube about 8 in. long, extending from the pharynx to the proventriculus and enlarged in the interclavicular region into a diverticulum, the crop, which lies to the right of the median plane. Except in the region of the crop, the oesophagus lies dorsal to the trachea. Histologically the oesophagus is composed of a thin outer connective tissue coat, within this a thin longitudinal muscular coat and a thick circular muscular coat of unstriated muscle, 
followed by a thin submucous layer. Bounding the submucous layer is a well-developed muscularis mucosae consisting of longitudinal unstriated muscle, very numerous mucous glands, and an internal stratified squamous epithelium. The crop resembles the oesophagus in its histological structure, except that there are no mucous glands present in the diverticulum except at its junction with the oesophagus. At its posterior end the oesophagus communicates with the proventriculus, or true stomach, which is simple and tubular, more muscular than the oesophagus and somewhat spongy in texture owing to the presence of much gland tissue. The internal epithelium is simple columnar, formed into simple tubular glands. In the mucous layer underlying the tubular glands is a well-developed layer of lobular glands, each lobule consisting of a number of tubular glands opening into a central cavity which in turn communicates with the lumen of the proventriculus by a duct. The epithelium of the secreting tubules has a characteristic crenulated appearance, each cell being separated from its neighbours except at the base. The epithelium lining the central cavity and its duct is simple columnar. At the base of the mucous coat is a well-developed muscularis mucosae running in a longitudinal direction; below this is the usual muscular layer, consisting of a well-developed circular, and a poorly developed external longitudinal, layer, bounded in turn by a serous connective tissue coat.

The proventriculus communicates with the gizzard, which is a dense compact oval muscular structure forming a flattened biconvex disc. It consists of two very dense and thick lateral muscles in apposition to one another, and two rather thin intermediate muscles, one arising in the region of the proventricular and duodenal openings and the other at the caudal end. These muscles are inserted into two broad sheets of tendon on the flattened lateral surfaces of the gizzard. The interior cavity of the gizzard thus resembles a flattened dumb-bell, the flattened arm of the dumb-bell forming the cavity between the lateral muscles, and the rounded ends the cavities of the intermediate muscles. The internal lining of the gizzard consists of a thick tough corrugated layer of keratin-like material, which is formed from the secretion of a layer of simple tubular glands present in the mucous coat. The epithelium of the glands is simple columnar.

The small intestine is about $4 \frac{1}{2} \mathrm{ft}$. long, the first portion, the duodenum, forming a loop within which lies the major part of the pancreas. The two bile ducts and the three pancreatic ducts open up into the duodenum at its distal end by a papilla. A gallbladder is present. The rest of the small intestine, the ileum and jejenum, is arranged in a coil supported by the mesentery.

The large intestine consists of the rectum, a short, straight tube 4-5 in. long, the cloaca, which forms the terminal portion of the gut, and two caecums, blind tubular sacs directed backwards along the terminal portion of the small intestine and linked to it by mesentery. The openings of the two caecums occur at the junction of the small intestine with the rectum. Each caecum is approximately 7 in. long and consists of a narrow constricted proximal portion and a dilated thinner-walled distal portion. The cloaca when distended forms a pear-shaped chamber, and is divided by transverse folds into the coprodeum into which the rectum opens, the urodeum into which the ureters and genital ducts open, and the proctodeum which terminates in the anus, 
a slit-like opening bounded by a dorsal and ventral lip of voluntary muscular tissue and lined with squamous stratified epithelium.

The minute structure of the small intestine, rectum and caecums conforms to the same general pattern, with minor variations in structure characteristic of each part. The epithelium is simple columnar throughout, villi are present, and simple tubular Lieberkühn's glands and crypts are characteristically present in the mucous coat, together with a muscularis mucosae. The submucous layer is poorly developed and not very evident. In the duodenum the villi are well developed and Lieberkühn's glands and crypts abundant, but there are no Brunner's glands. The muscularis mucosae is present, and the muscular coat consists of a prominent circular muscle layer and a thin longitudinal layer. In the ileum the villi are long and slender, and the muscularis mucosae consists of an inner longitudinal layer and an outer circular layer, the latter being in close contact with the circular muscle coat and in places so intimately connected with it as to render distinction between them difficult. In the rectum the villi are still well developed, but in the caecums the villi are short and Lieberkühn's crypts consist of simple tubular glands which open on the surface between the villi. The epithelium of the villi and glands is of the simple columnar type and mucous or goblet cells are numerous.

A special characteristic of the mucous layer of the gut wall is the presence of lymphoid tissue, which occurs as diffuse small patches or nodules. In the specimens examined by me, derived from a 2-month-old chicken, lymphatic tissue was present but scarce in the duodenum, in the ileum it occurred as occasional small nodules, in the rectum as somewhat larger patches; in the caecums it was diffuse and relatively abundant. According to Calhoun (1933), who has written an excellent monograph on the microscopic anatomy of the digestive tract of the fowl, the caecal lymphoid tissue increases with age.

\section{Correlation of structure with function}

Inspection of the gut contents of a recently killed fowl gives information on the functions of various parts of the gut. The function of the crop is seen to be storage, that of the gizzard grinding or trituration, and that of the small and large intestines digestion and absorption. The proventriculus is invariably found empty; the caecums as a rule are found to contain a chocolate-coloured pultaceous material, though on occasion they will be found empty.

The muscular activity of different parts of the gut, particularly the crop, proventriculus and gizzard, has been studied by balloon methods, in which the variations in pressure of air-inflated balloons inserted in these organs are recorded on rotating drums, showing the nature and frequency of the muscular contractions. Ashcraft (1930), by this method, found that the pressure curve of the proventriculus was similar to that of the gizzard, and that the gizzard contracted at rhythmic intervals of 20-30 sec. The time of passage of food through the gut has also been studied by giving known amounts of food, and recording the beginning and ending of the meal by markers consisting either of suitably coloured food, or of foods, such as oats, whose residues can be easily 
detected in the excreta. Such experiments have given very variable results; the reason for this will be apparent later.

In studying the movements of the gut and the passage of food through it, methods which involve surgical interference should be avoided. In 1929 in collaboration with A. E. Barclay, who was primarily responsible for the X-ray studies, I used barium meals, both grain and mash, to follow the passage of food through the gut, and a stethoscope to note the time relations of the gizzard movements. The mash was given wet, mixed with barium sulphate, and the grain (maple peas) was prepared by drilling a hole through each pea and filling it with a mixture of gelatine and barium sulphate, so that the passage of each individual grain could be detected. By these methods a composite picture of the behaviour of the musculature of the gut during and after a meal was obtained.

In a bird deprived of food so as to clear both the crop and the gizzard, the first two or three mouthfuls of food swallowed pass directly from the mouth to the gizzard, the time of passage varying from 15 to $30 \mathrm{sec}$. In the act of swallowing, the head and neck are rapidly jerked backwards and forwards, and a negative pressure is set up in the oesophagus. Food is thus rapidly transferred from the pharyngeal region of the mouth to the upper oesophagus, the danger of food passing into the upper laryngeal opening of the trachea being thereby avoided. At the same time air may be swallowed with the food mass (Pl. I, I). A peristaltic wave of contraction passes down the oesophagus and, owing to the pressure of the circular muscles of the gut wall, the food mass, which on its entry into the oesophagus is irregular in outline, takes on the characteristic shape of a food bolus and slowly travels along the oesophagus. By-passing the crop entrance it reaches the proventriculus, which it temporarily fills and distends. Here it remains for a short period, the length of stay, which is measured in seconds, apparently depending on the precise stage reached in the contraction cycle of the gizzard muscles. At one particular point in this cycle the gizzard is in a state of receptivity and the proventriculus contracts, forcing its contents into the gizzard.

After the gizzard has received its full complement of food, the character of the oesophageal peristaltic wave changes, and the contraction wave stops at the entrance of the crop instead of passing on, as hitherto, to the gizzard. As a result, subsequent food boluses travel down the oesophagus until they reach the crop entrance, remain here for a second or so and then drop down into the crop. Gradual filling of the crop thus occurs. Meanwhile, the gizzard is undergoing rhythmical contractions, the lateral muscles exerting strong pressure on the gizzard contents and so triturating the food, at the same time squeezing out the finer particles into the cavities formed by the intermediate muscles; this finer material then passes into the duodenum. This grinding process is aided by the small stones invariably present in the gizzard. During a meal, and as long as food is still reaching the gizzard, these contractions occur at intervals of 14-17 sec.; at other times the gizzard is less active and each contraction cycle may take as long as $30 \mathrm{sec}$.

After a meal is completed, subsequent filling of the gizzard takes place from the crop, the crop muscles undergoing contraction and thus bringing pressure to bear on the crop contents. From time to time a food bolus passes from the crop to the gizzard, 
and this process continues until the crop is empty. As the crop empties, the time interval between the passage of successive boluses lengthens; hence the first half of the food in a full crop reaches the gizzard in a shorter time than the second half. If, during a meal, the gizzard is in a receptive state at the precise moment when food is swallowed, the mouthful thus swallowed may pass direct to the gizzard instead of into the crop. It is this variability of destination that is responsible for the unreliability of results obtained from time experiments based on the use of markers, since the end marker may reach the gizzard while some of the unmarked food is still in the crop (Pl. 1, 2). During its passage through the gizzard, a certain amount of separation of the insoluble fibrous material from the starchy and more soluble material of the food takes place, and this partial retention of fibrous material may affect the digestibility coefficient of the crude fibre obtained in digestibility trials unless it is specially allowed for.

On reaching the small intestine the food mass undergoes digestion and absorption, and the residues are gradually propelled forward by the action of the muscles of the gut wall until they reach the rectum (P1. 2, I). Browne (1922), by slaughter methods on hens given coloured dough and dough mixed with sand and lead shot, showed that filling of the caecurns occurs from the rectal contents, only the liquid portion of these taking part. He further noted that the nature of the caecal contents varied with the condition of the normal excreta of the hen. In birds excreting fairly dry droppings the caecal contents formed an almost chocolate-brown pultaceous material consisting primarily of vegetable fragments and bacteria; in birds excreting semi-liquid droppings the caecal contents resembled the rectal contents. There is little doubt that a gradual filling of the caecums by the semi-fluid rectal contents takes place, and that the constricted entrances to the caecums prevent any material, other than liquid and finely comminuted solid particles, entering the caecums (PI. 2, 2). From time to time the caecums contract, expelling their contents, and Browne occasionally found the caecums to be empty on post-mortem examination. One primary function of the rectum and caecums is the absorption of water and soluble constituents of rectal contents. As the rectum fills it undergoes rapid vermicular movements, forcing the contents into the cloaca, which when fully distended discharges its contents to the exterior. Considerable absorption of the liquid and certain soluble constituents of the urine occurs in the cloaca, the unabsorbed urinary residues appearing as a white cap on the discharged faecal pellets.

\section{The tolerance of the fowl for fibre}

The processes of digestion in the fowl are rapid and efficient, and comparison of the results of digestibility trials show that its powers of digestion are akin to those of the pig for all nutrients other than crude fibre. Hence the digestibility coefficients of lowfibre foods are similar in the pig and the fowl, but for high-fibre foods this is not true. Steinmetzer (1924) first demonstrated by X-ray methods the rapidity of passage of food through the gut of the fowl, $2 \mathrm{hr}$. elapsing between the commencement of a meal and the first appearance of food residues in the excreta. In Steinmetzer's experiments the first appearance of food in different parts of the gut, timed from the commencement of the meal, was as follows: crop, within a few seconds; gizzard, 30 sec.; duodenum, 
15 min.; cloaca, 2 hr. My own observations with both mash and grain agreed with Steinmetzer's, with the exception that the time taken to reach the duodenum was $10 \mathrm{~min}$.

Owing to this rapidity of passage of food through the gut, coupled with the absence of cellulases in the fowl's digestive juices, it is unlikely that much digestion of crude fibre can occur, there being only two possible sites in the gut, namely, the crop and the caecums, where food can remain sufficiently long to enable bacterial digestion of fibre to occur. Moreover, the periodical emptying of the crop and the caecums discourages the build-up of a bacterial flora such as occurs in the rumen or large intestine of other farm animals. Nevertheless, evidence shows that some digestion of fibre does occur in the fowl. Radeff (1928) attacked the problem by studying the effect of the removal of the caecums on the digestion of crude fibre, and found that, whereas the digestibility of the crude fibre in barley was nil in both the normal bird and that deprived of caecums, with wheat and maize the digestibility coefficients for fibre were $5 \cdot 7 \mathrm{I}$ and $17.1 \%$, respectively, for the normal bird, but $1 \cdot 42 \%$ and nil for the bird deprived of caecums. Radeff thus established the fact that digestion of fibre occurs in the caecums and that little or none occurs in the crop.

Radeff's results were subject to the criticism that the mechanical hold-up that occurs in the gizzard was not taken into account, and Henning (1929) re-investigated the problem by methods in which the effect of this was overcome. In Henning's experiments the digestibility coefficients for crude fibre were as follows: pure cellulose (filterpaper) 0.0 , whole barley 0.0 , ground barley 0.24 , whole wheat $5 \cdot 1$, ground wheat $6 \cdot 78$, whole maize 19.72, ground maize 19.76, raw peas $7 \cdot 03$, cooked peas $0 \cdot 0$, cooked potato peel $9 \cdot 2$, oats $9 \cdot 25$, raw white cabbage $21 \cdot 07$, cooked cabbage $15 \cdot 68$, raw savoy cabbage 14.7. Using Radeff's operated bird, Henning obtained a digestibility of $0.0 \%$ for crude fibre in maize and of $1.31 \%$ in oats. Henning's results not only substantiated Radeff's finding that in the fowl the caecums are the chiet site of crude-fibre digestion, but also showed that such digestion is not materially aided by grinding the food, and is actually depressed by cooking. The variation between different foods, coupled with the zero result obtained with filter-paper, shows that the digestibility of crude fibre is associated with its chemical composition and that cellulose per se is indigestible. Stotz \& Brüggemann (I933) showed further that the digestibility of crude fibre varied considerably with different samples of the same food; they obtained digestibility coefficients varying from $0 \cdot 0$ to $3 \mathrm{I} \cdot 5$ with winter and summer barleys from different sources.

Mangold \& Hock (1938) found that pigeons digested protein and fat better than hens, but that they dealt with crude fibre and nitrogen-free extract less effectively, although rye, oats and wheat were an exception so far as the digestion of crude fibre was concerned. Brüggemann (193I) compared the digestion of crude fibre in the hen, pigeon, duck and goose. In the pigeon he found that the digestion of crude fibre was not localized in a particular site but occurred throughout the gut, and that the digestive powers of the pigeon for crude fibre in maize, yellow peas, wheat and barley were greater than those of the hen. Although the results of Mangold \& Hock and Brüggemann conflict so far as maize is concerned, on balance it would appear that the pigeon 
deals more effectively with crude fibre than the hen. The duck and the goose appear to possess similar powers of digestion for crude fibre, but are less efficient than the hen, an unexpected result in view of the fact that their natural diet consists largely of vegetable and plant foods.

On the whole it would appear that in ducks, hens and geese crude fibre plays a minor part in the supply of digestible nutrients, the importance of such digestion as occurs consisting rather in the setting free of the contents of plant cells for attack by the digestive juices. Thus, Halnan (1944) found that, whereas with raw potatoes the cell walls formed a barrier protecting the starch grains from the action of the digestive juices, this barrier was removed by cooking. As a result, the digestibility coefficient of the nitrogen-free extract rose from 18.3 in raw potatoes to 89.5 in cooked potatoes.

In considering the tolerance of birds for fibre, a distinction should be made between the fibre naturally present in the food and fibrous material added as a diluent, the former having a relatively greater effect on the availability of the food than the latter. Thus, in digestibility trials with varieties of oats, Halnan (1928) obtained a digestibility coefficient of 76.5 for the nitrogen-free extract of oats with an $8.7 \%$ fibre content, of 68.5 for oats with a $9.5 \%$ fibre content, and of 66.7 for oats with an $11.4 \%$ fibre content. An increase in the fibre naturally present in the food thus adversely affected the availability of the nitrogen-free extract. On the other hand, Morris, Thompson \& Heller (1932), using lucerne-stem meal and oat hulls as fibre-rich supplements, increased the fibre content of a chick mash from $3 . \mathrm{I}$ to $10.8 \%$ without adversely affecting the utilization of the basal mash. Digestibility trials showed no depression of digestibility of the protein or fat when these fibre-rich supplements were used, but for the nitrogen-free extract there was an apparent drop from $79 \cdot 0$ to $71 \cdot 5 \%$. This drop, however, was presumably caused by the admixture of a fibre-rich supplement, having a digestibility coefficient for the nitrogen-free extract of 34.7 , with the basal mash whose corresponding digestibility coefficient was $79 \cdot 0$, since calculation of the digestibility coefficient for the nitrogen-free extract of a mixture consisting of 100 parts basal mash and 30 parts lucerne-stem meal gave the theoretical figure of $71^{\circ} 5$. The added fibre consequently acted as a diluent only, and had no effect on the availability of the mash to which it was added.

Owing to this differing effect of fibre in a ration according to its presence as a natural ingredient of the food or as a diluent, it is difficult to define precise limits for fibre in poultry mashes. A poultry mash high in fibre, but composed of low-fibre and highfibre foods, may give better results than a mash of the same fibre content but composed of foods all moderately high in fibre. The effect of the level of fibre in poultry foods on their nutritive value has been demonstrated by Axelsson (1939). Using his data, I have estimated that, to supply the maintenance energy requirements of a $4.5 \mathrm{lb}$. bird, $2.5 \mathrm{oz}$. of a mash containing $7.5 \%$ fibre, $3.8 \mathrm{oz}$. of a mash containing $22.5 \%$ fibre and $6.33 \mathrm{oz}$. of a mash containing $32.5 \%$ fibre would'be required. If a daily food consumption of $4 \mathrm{oz}$. is assumed, it will be seen that no margin for production is available if the level of fibre in a mash reaches $22.5 \%$, and that, with a fibre content of $7.5 \%, 37.5 \%$ of the food is available for production. Although, therefore, it is not possible to state a precise limit for the level of fibre in poultry-food mixtures, it is apparent from the 
point of view of production that a level of about $7.5 \%$ would be a desirable upper limit, allowing a reasonable amount of food nutrients for productive use after the maintenance requirements have been met. With regard to the lower limit, Davis \& Briggs (1947) demonstrated beneficial effects from the inclusion of $5 \%$ of a commercial cellulose preparation in a synthetic fibre-free chick diet. As measured by the ratio of gain in weight to food intake, the addition of $5-15 \%$ of cellulose improved the feeding efficiency, but lessened efficiency followed the use of $20 \%$ or more of cellulose. The maximum efficiency was obtained at the $5 \%$ level of cellulose intake; this figure can therefore be regarded as a minimum level for crude fibre in poultry rations. Apart from its value in increasing the biological efficiency of the diet, the inclusion of fibre corrects the tendency to the production of loose, watery droppings which is associated with the use of fibre-free foods.

\section{SUMMARY}

I. The general structure, macroscopic as well as microscopic, of the gut of the fowl is described, and the correlation of structure with function outlined.

2. The ability of the fowl to digest crude fibre, and the effect of the level of crude fibre in poultry mashes upon the availability of other food nutrients are discussed.

\section{REFERENCES}

Ashcraft, D. W. (1930). Amer. F. Physiol. 93, 105.

Axelsson, J. (1939). World's Poult. Congr. vit. Cleveland, Ohio, p. 165.

Browne, T. G. (1922). F. comp. Path. 35, I2.

Brüggemann, H. (1931). Arch. Tierernähr. Tierz. 5, 89; summary by Bartsch, O. (1932). Arch. Gefiügelk. 6, 276.

Calhoun, M. L. (1933). Iowa St. Coll. F. Sci. 7, 261.

Davis, F. \& Briggs, G. M. (1947). F. Nutrit. 34, 295.

Halnan, E. T. (1928). F. agric. Sci. 18, 634 .

Halnan, E. T. (1944). F. agric. Sci. 34, 139.

Henning, H. T. (1929). Landw. VersSta. 108, 253.

Mangold, E. \& Hock, A. (1938). Arch. Gefligelk. 12, 334.

Morris, L., Thompson, R. B. \& Heller, V. G. (1932). Poult. Sci. 11, 2 I9.

Radeff, T. (1928). Biochem. Z. 193, 192.

Steinmetzer, K. (1924). Pfiüg. Arch. ges. Physiol. 206, 500.

Stotz, H. \& Brüggemann, H. (1933). Arch. Gefligelk. 7, 202.

\section{EXPLANATION OF PLATES}

X-ray photographs illustrating passage of food through gut of fowl.

\section{PLATE I}

1. Act of swallowing. The food in the mouth has just entered the oesophagus; at the same time a bolus of food from the crop has reached the proventriculus. Note the irregular outline of the food mass in the oesophagus, the retracted position of the neck, the distension of the crop by air sucked in with the food mass, and the regular outline of the food bolus in the proventriculus.

2. Lateral view of bird feeding from a cup. The bird has just begun to feed on a barium sulphate mash. Some flecks of mash will be noted in the oesophagus, and several food boluses have entered the crop and form an irregular black mass at the bottom of the crop, which, it will be noted, is partly distended with air. The remains of the previous meal (normal mash) show as a lighter-coloured mass in the forward region of the crop. A bolus of food, partly obscured by the neck bones, can be seen at the entrance of the crop, and another food bolus will be noted in the region of the proventriculus. Both these boluses were derived from the same mouthful of food, the former dropping into the crop shortly after the X-ray photograph was taken, the latter passing on to the gizzard. This illustrates the difficulty of obtaining reliable data on the time of passage of food through the gut of a fowl by the use of markers. 
E. T. Hai nan. The architecture of the avian gut and tolerance of crude fibre Plate I

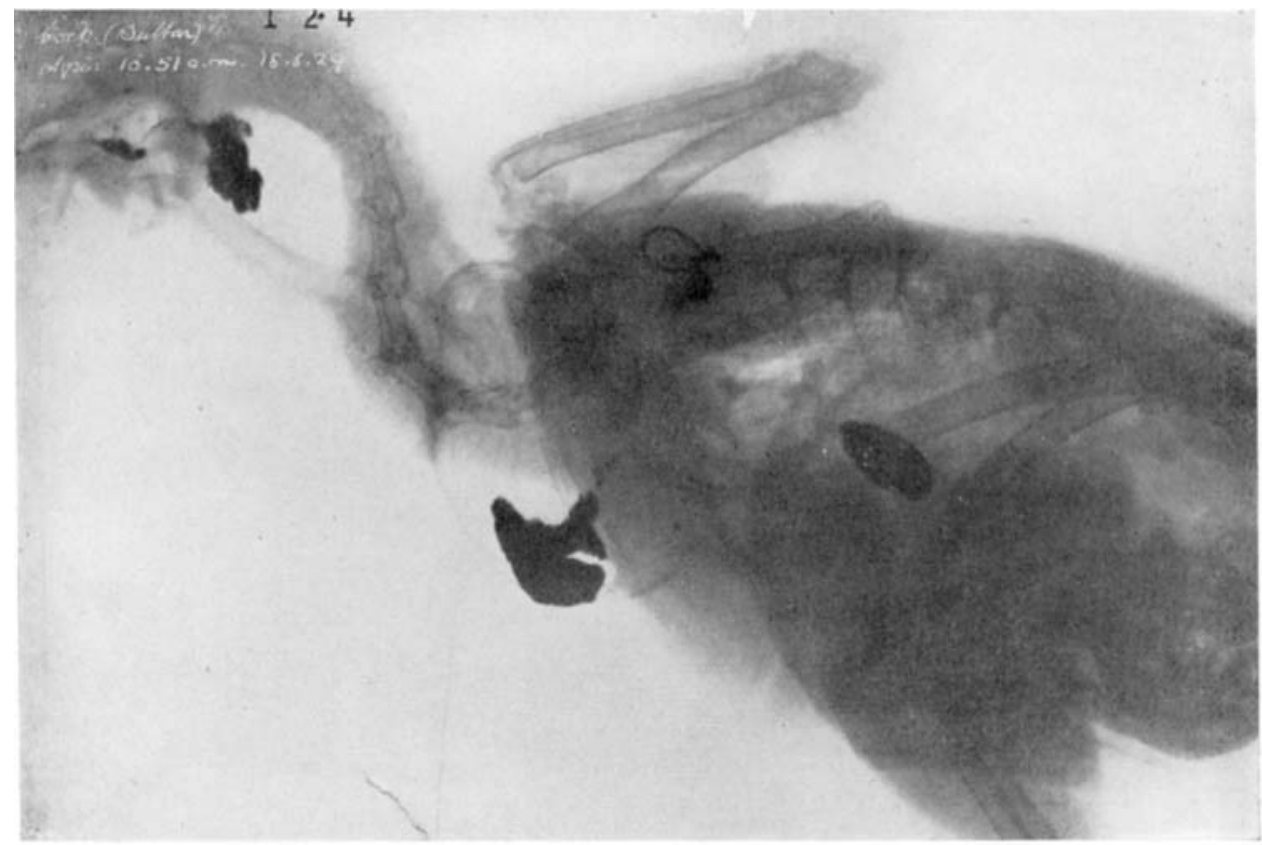

1

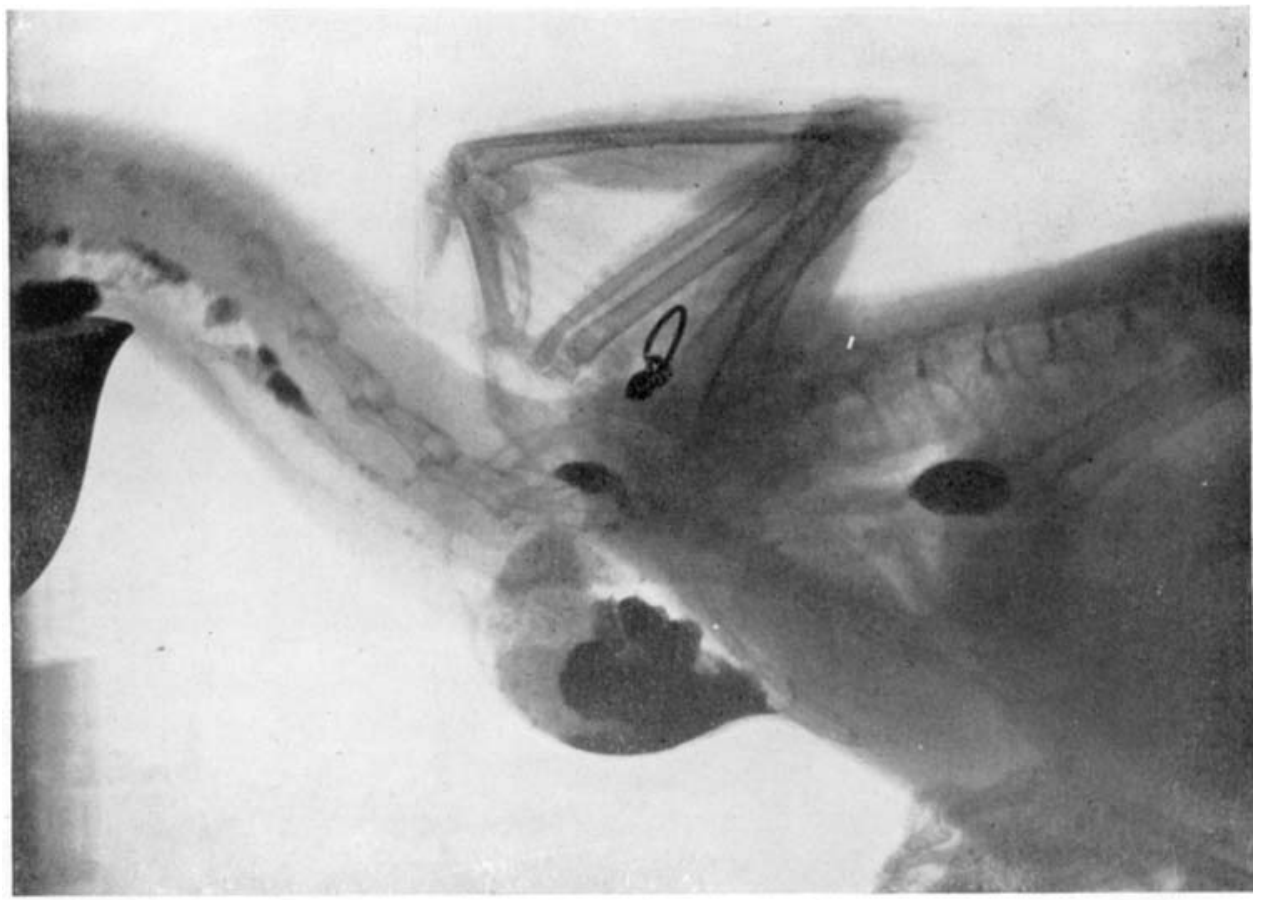

2

British Fournal of Nutrition, Vol. 3, Nos. 2 and 3 
E. 'T'. Halnan. The architecture of the avian gut and tolerance of Crude fibre Plate 2
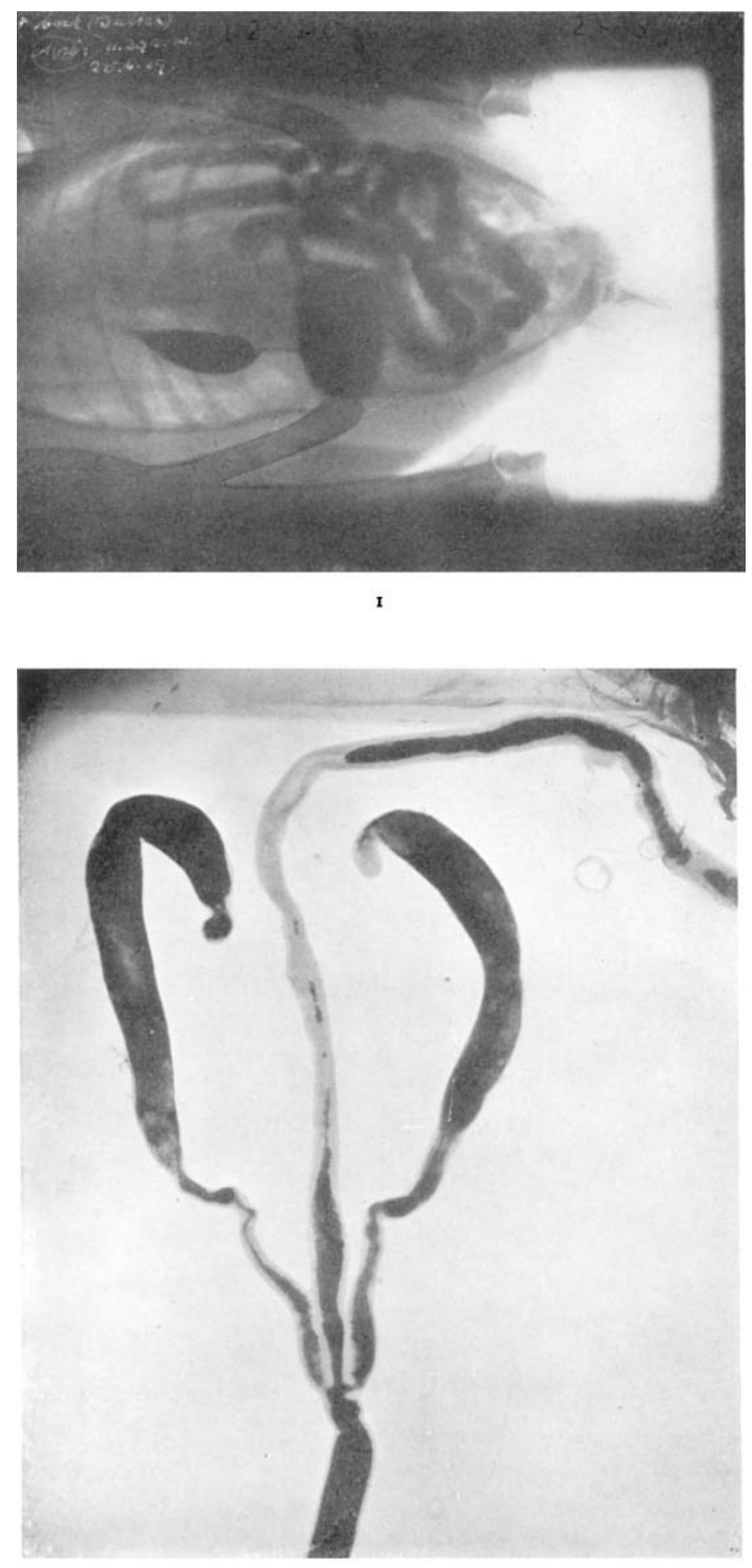

2

British Fournal of Nutrition, Vol. 3 , Nos. 2 and 3 
PLATE 2

1. Dorsal view of body in abdominal region. The relative positions of the proventriculus, gizzard and intestines are clearly outlined.

2. View of caecums injected with barium sulphate mash. The caecums were injected with barium sulphate mash via the rectum. Note the constriction at the junction of the caecums and rectum with the small intestine, and the constricted proximal portions and dilated distal portions of the caecums.

\section{The Requirements of Poultry for Aneurin, Choline, Folic Acid, Nicotinic Acid, Pantothenic Acid and Riboflavin}

\section{By J. Duckworth and G. M. Ellinger, Rowett Research Institute, Bucksburn, Aberdeenshire}

An assessment of the adequacy of vitamin supplies in rations for any class of stock requires information of two kinds: (I) the quantities of the different vitamins in feeds, and (2) the requirements of the animals of the class in question for these vitamins. Information on these two categories is given below.

The data for the vitamin content of common poultry feeding-stuffs have been collected from recent literature. These are given in Tables $I$ and 2 . Where individual values are not given, either data could not be found or the values reported were too inconsistent for an average value to be reliable.

Information about the vitamin needs of baby chicks is extensive. The requirements of growing and adult birds are less well known. The differences in requirements for producing hatching eggs, as compared with table eggs, have not been extensively studied. Few workers have extended their investigations beyond the question of hatchability to include studies of the effect of vitamin levels in the hen's diet upon viability and vigour of the chicks.

Standards of vitamin requirements of poultry were first put forward by a committee of the (U.S.A.) National Research Council (Committee on Animal Nutrition, 1944). A revision recently appeared (Bird, 1948 ). The recommended allowances are given in Table 3. The original values included a $20 \%$ margin of safety above estimated adequacy. This has been subtracted in compiling the present table. There were several omissions in the original table; some of these have been filled by values secured from the recent literature, a survey of which follows.

\section{Recent work on vitamin requirements of poultry}

Aneurin. There has been no recent report on the requirements of poultry for aneurin.

Choline. Only the chick seems to require a dietary source of choline; in older birds synthesis occurs. Hens given a semi-synthetic diet containing only $0.04 \%$ choline had an output of choline in eggs of four or five times the intake (Ringrose \& Davis, 1946). When a natural diet, extracted with boiling neutral ethanol to reduce the choline content to $0.03 \%$, was given, egg production and hatchability were only slightly less than in birds receiving the same diet supplemented with choline to raise the level to $0.21 \%$ (Lucas, Norris \& Heuser, 1946). 